\title{
PORTUGAL: DESAFIOS NUM TERRITÓRIO EM MUDANÇA SEMINÁRIO EM HOMENAGEM AO PROFESSOR JORGE GASPAR
}

\author{
EduARDA MARQues DA COSTA ${ }^{1}$
}

Por iniciativa da área de investigação em Geografia Humana ${ }^{2}$ do Centro de Estudos Geográficos da Universidade de Lisboa, realizou-se no passado dia 28 de Novembro de $2007^{3}$, sob patrocínio do Magnífico Reitor, um seminário Internacional subordinado ao tema "Portugal: Desafios num Território em Mudança", que teve como objectivo homenagear a extensa e reconhecida obra do Professor Jorge Manuel Barbosa Gaspar e a sua actividade de Geógrafo e Planeador.

O seminário contou com a intervenção de vários colegas portugueses e estrangeiros, de diversas áreas científicas, cujas apresentações se organizaram em três grandes temas, designados por "Portugal Visto de Fora", "Portugal Visto pelos Geógrafos" e "Portugal - Outros Olhares", temas tratados ao longo de 4 sessões. Para a primeira sessão foram convidados oradores que apresentaram a sua perspectiva sobre a evolução de Portugal nos últimos 35 anos. Assim, na primeira sessão estiveram presentes, Bodo Freund da Universidade de Humboldt (Berlim), profundo conhecedor de Portugal, que descreveu a realidade encontrada na sua primeira viagem a Portugal, comparando-a com a actualidade, e Antoinne Bailly, professor aposentado da Universidade de Genebra, cuja intervenção se centrou sobre a evolução, em termos de posicionamento teórico, feita por Jorge Gaspar e outros geógrafos contemporâneos. Lorenzo Lopes Trigal da Universidade de Léon comentou as duas intervenções anteriores, enquadrando a evolução portuguesa no quadro ibérico.

O segundo painel de intervenções era composto por geógrafos e dividiu-se em dois grupos. O primeiro grupo, contou com a participação de Margarida Pereira da Universidade Nova de Lisboa e Rui Jacinto da Comissão de Coordenação da Região Centro (e Professor Convidado da Universidade de Coimbra) que apresentaram duas comunicações comentadas por João Guerreiro, Reitor da Universidade do Algarve. Questões

1 Professora Auxiliar da Universidade de Lisboa. Investigadora do Centro de Estudos Geográficos da Universidade de Lisboa. E-mail: eduardamcosta@netcabo.pt

2 Investigadores permanentes da Área de Investigação em Geografia Humana do Centro de Estudos Geográficos da Universidade de Lisboa que colaboraram na organização do evento e na elaboração do Livro: Alina Esteves, Carminda Cavaco, Diogo Abreu, Eduarda Marques da Costa, Eduardo Brito Henriques, Iva Pires, Jorge Rocha, José Manuel Simões, Luís Moreno, Margarida Queirós, Maria Alexandre Lousada, Maria Lucinda Fonseca, Mário Vale, Nuno Marques da Costa, Paulo Morgado, Teresa Alves.

3 O Seminário realizou-se no Salão Nobre da Reitoria da Universidade de Lisboa. 
em torno dos problemas urbanos e os processos de desenvolvimento urbano e regional foram por eles abordadas. O segundo painel "Portugal Visto pelos Geógrafos" teve lugar após o almoço com as intervenções de Diogo Abreu e Mário Vale, comentadas por Lucinda Fonseca, todos membros da Universidade de Lisboa. As intervenções centraram-se nas perspectivas de desenvolvimento para Portugal.

A sessão intitulada "Portugal - Visto de Fora" reuniu académicos e colegas de outras áreas científicas, que colaboraram profissionalmente com Jorge Gaspar. Neste contexto, falaram José Manuel Fernandes, da Universidade Técnica de Lisboa e Frank Hansen, da Universidade de Copenhaga, intervenções comentadas por Manuel Costa Lobo da Universidade Técnica de Lisboa.

O seminário prosseguiu com a apresentação do livro intitulado "Geophilia - O sentir e os sentidos da Geografia. Homenagem a Jorge Gaspar", numa edição do Centro de Estudos Geográficos, com mais de 700 páginas, organizada pelos vários membros da Linha de Acção - Geografia Humana. A edição conta com a participação de 22 autores nacionais e 15 estrangeiros, 12 testemunhos, mais de 400 assinaturas na Tabula Gratulatoria, uma lista das publicações de Jorge Gaspar e, ainda, uma biografia escrita por José Manuel Simões. No seguimento da apresentação do livro teve lugar a conferência magistral do Professor Jorge Gaspar.

A sessão de encerramento contou com a presença do Secretário de Estado do Ordenamento do Território e das Cidades, do Magnifico Reitor da Universidade de Lisboa e do Presidente do Conselho Cientifico da Faculdade de Letras da Universidade de Lisboa. O seminário juntou mais de 250 pessoas, das quais cerca de 120 estiveram também presentes no jantar que decorreu após o encerramento da sessão. 